\title{
BMJ Open Carrier prevalence and risk factors for colonisation of multiresistant bacteria in Danish emergency departments: a cross- sectional survey
}

Helene Skjøt-Arkil, ${ }^{\oplus 1,2}$ Christian Backer Mogensen, ${ }^{\oplus 1}$ Annmarie Touborg Lassen, ${ }^{3}$ Isik S Johansen, ${ }^{4}$ Ming Chen, ${ }^{5}$ Poul Petersen, ${ }^{6}$ Karen V Andersen, ${ }^{7}$ Svend Ellermann-Eriksen, ${ }^{8}$ Jørn M Møller, ${ }^{9}$ Marc Ludwig, ${ }^{10}$ David Fuglsang-Damgaard, ${ }^{11}$ Finn Erland Nielsen, ${ }^{12}$ Dan B Petersen, ${ }^{13}$ Ulrich S Jensen, ${ }^{14}$ Flemming S Rosenvinge ${ }^{15}$

To cite: Skjøt-Arkil H, Mogensen CB, Lassen AT, et al. Carrier prevalence and risk factors for colonisation of multiresistant bacteria in Danish emergency departments: a crosssectional survey. BMJ Open 2019;9:e029000. doi:10.1136/ bmjopen-2019-029000

- Prepublication history and additional material for this paper are available online. To view these files, please visit the journal online (http://dx.doi. org/10.1136/bmjopen-2019029000).

Received 7 January 2019 Revised 28 May 2019 Accepted 7 June 2019

Check for updates

(C) Author(s) (or their employer(s)) 2019. Re-use permitted under CC BY-NC. No commercial re-use. See rights and permissions. Published by BMJ.

For numbered affiliations see end of article.

Correspondence to

Dr. Helene Skjøt-Arkil;

Helene.Skjoet-Arkil@rsyd.dk

\section{ABSTRACT}

Objectives The aim of this study was to describe the carrier prevalence and demographic variation of four different multiresistant bacteria (MRB) among acute patients in Danish emergency departments (EDs): methicillin-resistant Staphylococcus aureus (MRSA), carbapenemase-producing enterobacteria (CPE), extendedspectrum beta-lactamase-producing enterobacteria (ESBL) and vancomycin-resistant enterococci (VRE), and to analyse the association of MRB carriage to a range of potential risk factors.

Design Multicentre descriptive and analytic crosssectional survey.

Setting Eight EDs and four clinical microbiology

departments in Denmark.

Participants Adults visiting the ED.

Main outcome measures Swabs from nose, throat and rectum were collected and analysed for MRSA, ESBL, VRE and CPE. The primary outcome was the prevalence of MRB carriage, and secondary outcomes relation to risk factors among ED patients.

Results We included 5117 patients in the study. Median age was 68 years (54-77) and gender was equally distributed. In total, $266(5.2 \%, 95 \% \mathrm{Cl} 4.6$ to 5.8) were colonised with at least one MRB. No significant difference was observed between male and female patients, between age groups and between university and regional hospitals. Only 5 of the 266 patients with MRB were colonised with two of the included bacteria and none with more than two. CPE prevalence was $0.1 \%$ ( $95 \% \mathrm{Cl} 0.0$ to 0.2$)$, MRSA prevalence was $0.3 \%$ ( $95 \% \mathrm{Cl} 0.2$ to 0.5$)$, VRE prevalence was $0.4 \%(95 \% \mathrm{Cl} 0.3$ to 0.6$)$ and ESBL prevalence was $4.5 \%(95 \% \mathrm{Cl} 3.9$ to 5.1$)$. Risk factors for MRB carriage were previous antibiotic treatment, previous hospital stay, having chronic respiratory infections, use of urinary catheter and travel to Asia, Oceania or Africa.

Conclusion Every 20th patient arriving to a Danish ED brings MRB to the hospital. ESBL is the most common MRB in the ED. The main risk factors for MRB carriage are recent antibiotic use and travel abroad.

Trial registration number NCT03352167; Post-results.

\section{Strength and limitations of this study}

- This is the first study to describe and analyse a large number of possible risk factors in acute adult patients screened for extended-spectrum beta-lactamase-producing enterobacteria, vancomycin-resistant enterococci, methicillin-resistant Staphylococcus aureus and carbapenemase-producing enterobacteria.

- It is a multicentre study covering the main part of Denmark.

- Many of the results are reported with some degree of uncertainty, reflected in wide Cls, especially in subgroup analysis.

- External validity of this study is restricted to countries with a low multiresistant bacteria prevalence.

\section{BACKGROUND}

Multiresistant bacteria (MRB) is an increasing problem globally. ${ }^{12}$ In Denmark, attention has been focused on methicillin-resistant Staphylococcus aureus (MRSA), but there has also been an increase in the prevalence of extended-spectrum beta-lactamase-producing enterobacteria (ESBL), vancomycin-resistant enterococci (VRE) and carbapenemase-procuding enterobacteria (CPE). ${ }^{34}$

The consequences of the increasing bacterial resistance to antibiotics are multiple and one of the greatest menaces to human health. ${ }^{5}$ Spread of MRB leads to increased healthcare costs, increased morbidity and mortality, ${ }^{7}$ increased risk of surgical site infection $^{8}$ and complicates treatments of malignancies and transplantations, ${ }^{9} 10$ which are dependent on effective infection control.

Antibiotics are used in many areas of the hospital. The emergency departments (EDs) are key players in the in-hospital use of 
antibiotics and in the early identification of patients who are colonised with MRB since the vast majority of patients are admitted through these departments.

According to the Global Action Plan on antimicrobial resistance by $\mathrm{WHO}$, one of the particularly important gaps in knowledge is information on incidence, prevalence, range across pathogens and geographical pattern related to antimicrobial resistance. ${ }^{6}$ There is currently very sparse knowledge about both prevalence and risk factors for colonisation with MRSA, ESBL, VRE and CPE in acutely admitted patients. In order to clarify the extent of the problem and to prioritise the preventive response to the spread of MRB, it is necessary to know the prevalence of these bacteria in patients passing through the EDs. To develop evidence-based screening tools to identify carriers of resistant bacteria among the acutely admitted patients, systematic collection of information on risk factors and exposures is required. Since a certain geographical variation in carrier prevalence is expected, it is desirable to include EDs from different geographical regions.

The aim of this study was first to describe the prevalence and demographic variation of MRSA, CPE, ESBL and VRE carriage among acute patients in eight different Danish EDs and second to analyse the association of MRB carriage to a range of potential risk factors.

\section{METHODS}

This study is part of the Danish multicentre study Antibiotic Resistance in Emergency Departments (AB-RED). The study protocol has been published and we refer to this publication for detailed information. ${ }^{11}$

The AB-RED study was designed as a multicentre descriptive and analytic cross-sectional survey of patients who were visiting one of eight Danish EDs geographically covering the whole country apart from the capital region.

The study was reported in accordance with the Strengthening the Reporting of Observational Studies in Epidemiology guideline. ${ }^{12}$

\section{Study setting}

The study took place in EDs at the university hospitals in Odense, Aarhus, Aalborg and Køge, and the regional hospitals in Aabenraa, Herning, Hjørring and Slagelse, which in total represent four of the five Danish regions. A Danish ED corresponds to an acute medical ward.

All the included EDs received patients, either referred by a general practitioner or the prehospital emergency medical services. The EDs and hospitals provide services at specialist level in emergency medicine, internal medicine, cardiology, orthopaedic and surgery. All hospitals are public hospitals and provide care free of charge. There are no private acute care hospitals in Denmark.

\section{Participant timeline}

Enrolment to the study commenced on 8 January 2018. Due to local conditions, some of the participating departments included patients from 1 February 2018. Enrolment continued until the predefined sample size for each department had been reached. The last patient was enrolled in the end of April 2018.

\section{Sample size}

A Danish study showed an MRSA prevalence in acutely admitted patients of $0.9 \%$ in an ED. ${ }^{13}$ It was assumed that VRE and CPE have a lower occurrence and ESBL a higher occurrence. ${ }^{3}$ We aimed at a national sample size of at least 5000 patients, which would allow a prevalence of MRB of $0.5 \%$ to be detected with $95 \%$ CI of $\pm 0.14 \%, 1 \%$ prevalence with $\pm 0.20 \%$ and $10 \%$ prevalence with $\pm 0.6 \%$. ${ }^{11}$

\section{Eligibility criteria}

Patients $>18$ years of age, who presented to the EDs, were mentally competent and able to give consent were invited to participate in the study. Patients were excluded if they had been admitted $>16$ hours or if sampling from the rectum, nose or throat was hindered by anatomical or surgical reasons. Since the aim of the study was to assess the impact on the ED of MRB, patients who had been included before were allowed to be included again in a later admission.

In the study protocol, an inclusion criteria was that patients should have been at the department at least 4 hours before enrolment. Due to differences in ED organising, it became difficult to maintain this criterion, thus this was deviated from the study protocol.

\section{Recruitment}

Patients visiting the ED were contacted as early as possible during the enrolment process by a project employee who informed both verbally and in writing about the project. Privacy was secured during the information and no treatment was delayed because of the enrolment. One hour of consideration time was offered to the patients.

\section{Data collection methods}

Interview

The project staff in the EDs had a healthcare background (nurse or medical student) and included patients from 07:00 to 22:00 hours. All project staff received a 1/2 day training and supervised practice in interview and swab collection at the beginning of the project. Data quality and swab collection practice were supervised daily by the project manager and local coordinators.

All included patients were asked a range of questions concerning risk factors for carriage of MRB (online supplementary appendix). The questions included were in part based on the Danish National Board of Health's guidance on preventing spreading of MRSA. ${ }^{14}$ In summary, these questions included demographical information, recent treatment with antibiotics, exposure to MRB in working places, especially different sorts of institutions, professional contact to animal farms, travelling activities and treatments in hospitals and clinics outside Denmark. In addition, questions about individual risk factors like skin and lung diseases were included. 


\section{Collection of swabs}

Immediately after the interview the patient was swabbed by the project staff. Swabs for MRSA were obtained from the mucosal surface of the anterior nares and the surfaces of the tonsils and pharynx (ESwab, Copan, SSI Diagnostica, Hillerød, Denmark). The sampling procedure followed the guidelines of the National Board of Health.

Rectal swabs for VRE, CPE and ESBL were obtained by rotating a swab against the mucosal surface $1-2 \mathrm{~cm}$ beyond the anal sphincter (FecalSwab, Copan).

The three swabs were labelled with barcodes containing information on project department and a unique project sequence number. All samples were sent to the regional department of clinical microbiology.

\section{Outcomes}

The primary outcome was the presence of MRB (MRSA, ESBL, VRE and CPE) in adult patients in the ED. The secondary outcome was the association between risk factors and MRB carrier stage.

\section{Microbiological analysis}

The collected samples were examined at the Departments of Clinical Microbiology at Aalborg University Hospital, Aarhus University Hospital, Odense University Hospital and Slagelse Hospital. The same method of analysis was applied to all four departments. All analyses followed the procedure described in the protocol article without deviations from the protocol. ${ }^{11}$

Briefly outlined, samples were screened with commercially available, selective, chromogenic agar media ( MRSA: CHROMagar MRSA II agar, ESBL: CHROMagar ESBL bi-agar (Becton Dickinson, Heidelberg, Germany)), (CPE: chromID CARBA SMART agar, VRE: chromID VRE agar (bioMérieux, Marcy-l'Etoile, France)). A preceding enhancement broth step was used for both VRE and MRSA. All isolates were identified by mass spectrometry (Matrix-Assisted Laser Desorption-Ionization - time of flight) (MALDI-TOF)) and the presence of resistance genes in MRSA $(m e c \mathrm{~A} / m e c \mathrm{C}) \mathrm{VRE}(\operatorname{van} \mathrm{A} / \operatorname{van} \mathrm{B})$ and $\mathrm{CPE}$ $\left(b l a_{\mathrm{KPC}} / b l a_{\mathrm{NDM}} / b l a_{\mathrm{VIM}} / b l a_{\mathrm{OXA}-48} / b l a_{\mathrm{IMP}}\right)$ was confirmed by PCR. ESBL production was confirmed phenotypically (synergism between clavulanic acid and cefotaxime, ceftazidime and/or cefepime).

\section{Data management and analysis}

All patients were provided with a unique project sequence number, which was used throughout the project in the interviews and processing of microbiological samples to secure anonymity. The answers from the interviews were entered directly to an electronic questionnaire (SurveyXact, Rambøll, Aarhus, Denmark). Data were transmitted directly to central secured data file storage. Microbiological test results were merged with the interview data using the project sequence number.

The carrier prevalence of the different MRB were calculated as percentage including a $95 \% \mathrm{CI}$, at regional level and national level and described with relation to region, hospital category, sex and age. We analysed differences between groups with $\mathrm{X}^{2}$ test or Fisher's exact test. Non-participant analysis was performed. The association between risk factors and MRB carrier stage was calculated using univariate logistic regression and multivariate logistic regression. Cochran's rule was used and results expressed in ORs. The data analyses were conducted in STATA V.14 (Metrika, Stockholm, Sweden).

\section{Ethics approval and consent to participate}

Informed written consent with signature was obtained from all participants before inclusion in the study. The patients had the right of revocation in which case the patient data would be deleted from the study.

\section{Patient and public involvement}

The patients were not involved in the development of the research question, the study design or in the recruitment to and conduct of the study.

All included patients were asked, if they wanted to be informed of the results of the microbiological analysis of their sample. If they did, answers on whether they were colonised with MRB and which type were sent individually by electronic mail. The mail included a statement on what the patient should do and who they could contact for further information.

\section{RESULTS}

In total, 7186 adult patients visiting the ED were invited to participate and $5117(72 \%)$ of these were included in the analyses (figure 1 and table 1 ). The median age of

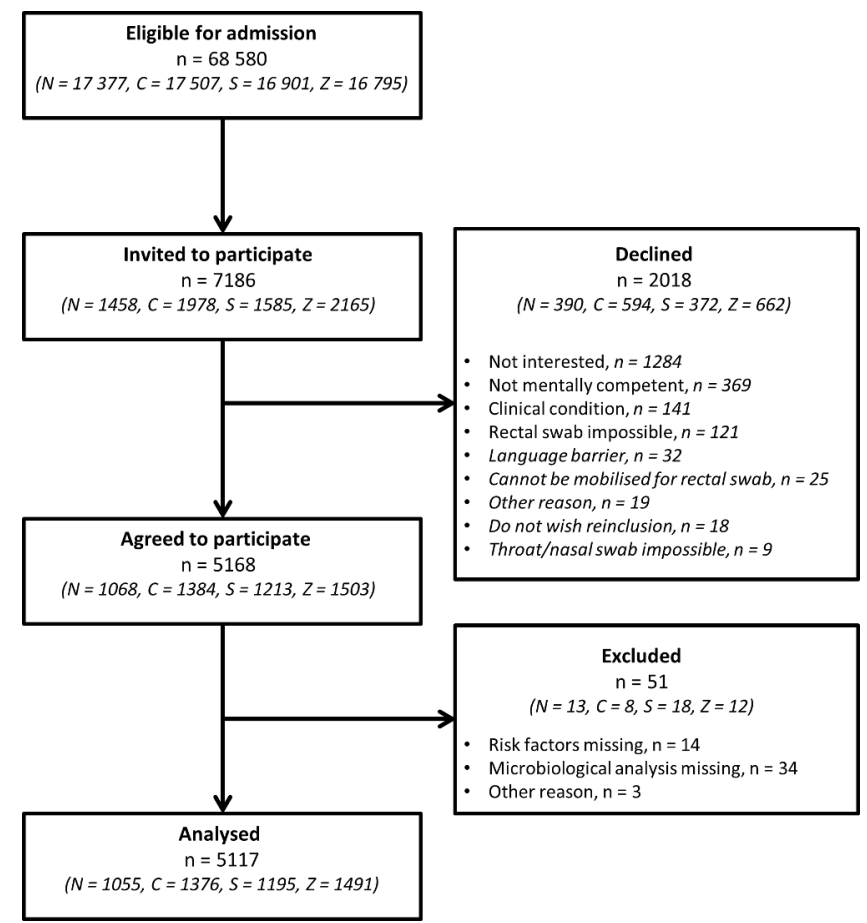

Figure 1 Patient flow in the study. C, Central Denmark; N, North Denmark; S, Southern Denmark; Z, Zealand. 


\begin{tabular}{|c|c|}
\hline & $\begin{array}{l}\text { Analysed } \\
\mathrm{n}=5117\end{array}$ \\
\hline Median age, years (IQR) & $68(54-77)$ \\
\hline Male $(49.7 \%)$ & $68(54-77)$ \\
\hline Female (50.3\%) & $68(53-78)$ \\
\hline Median time to lab, days (IQR) & $1(1-1)$ \\
\hline \multicolumn{2}{|l|}{ Type of hospital, n (\%) } \\
\hline University hospitals & 2203 (43\%) \\
\hline Regional hospitals & $2914(57 \%)$ \\
\hline \multicolumn{2}{|l|}{ Region, n (\%) } \\
\hline Zealand & $1491(29 \%)$ \\
\hline Central Denmark & $1376(27 \%)$ \\
\hline Southern Denmark & $1195(23 \%)$ \\
\hline North Denmark & 1055 (21\%) \\
\hline \multicolumn{2}{|l|}{ Hospital, n (\%) } \\
\hline Regional Hospital West Jutland & $811(16 \%)$ \\
\hline Slagelse Hospital & $777(15 \%)$ \\
\hline Zealand University Hospital & $714(14 \%)$ \\
\hline North Denmark Regional Hospital & $682(13 \%)$ \\
\hline Hospital of Southern Jutland & $644(13 \%)$ \\
\hline Aarhus University Hospital & $565(11 \%)$ \\
\hline Odense University Hospital & $551(11 \%)$ \\
\hline Aalborg University Hospital & $373(7 \%)$ \\
\hline
\end{tabular}

the study population was 68 years (IQR $54-77$ years) and gender was equally distributed.

Among the patients who declined to participate, there were fewer male patients ( $46 \%$ vs 50\%) and fewer patients with complains related to internal medicine $(49 \%$ vs $54 \%)$ than in the patients who accepted to participate. No age difference was found (67 years (IQR 46-80) vs 68 years (IQR 54-77)).

\section{Prevalence and demography of MRB}

In total, $266(5.2 \%)$ of the patients were colonised with at least one MRB (table 2). There was no significant difference between male and female patients $(5.5 \%$ vs $4.9 \%$, $\mathrm{p}=0.33)$, between age groups $(5.8 \%$ in those aged $50-64$ years vs $4.3 \%$ in those aged $>80$ years, $\mathrm{p}=0.11$ ), between university hospitals and regional hospitals $(5.3 \%$ vs $5.2 \%$, $\mathrm{p}=0.81$ ), but a significant difference between regions (Region of Central Denmark 6.5\% vs Region of Northern Denmark $3.9 \%, \mathrm{p}=0.004$ ).

Of the 266 patients with MRB, five patients were colonised with two different MRB (ESBL/VRE in three patients, CPE/VRE in one patient and ESBL/CPE in one patient). No patients were colonised with more than two MRB.

Of the 5117 included patients, $96(1.9 \%)$ were included more than once, and $10(0.2 \%)$ more than twice. Of the 266 MRB-positive patients, $8(3 \%)$ patients were re-attendances. Four $(1.5 \%)$ of these re-attendances were colonised at all inclusions (three patients with ESBL and one with VRE).

CPE was detected in four patients $(0.08 \%)$, three of these in Region Zealand. The MRSA prevalence was $0.3 \%$ nationally with significant differences between the regions (Region of North Denmark 0\% vs Region of Central Denmark $0.8 \%, \mathrm{p}=0.003)$. VRE was found in $0.4 \%$ of the patients, most common in the oldest group (18-40 years $0 \%$ vs $>80$ years $0.9 \%, p=0.004$ ), but with no significant differences between gender, region or type of hospital. The most common MRB colonisation was ESBL with a $4.5 \%$ prevalence, ranging from $3.7 \%$ to $5.2 \%$ between the regions $(\mathrm{p}=0.09)$ and no significant differences between gender and age.

In table 3, number of in vitro susceptible isolates are reported.

\section{Risk factors for colonisation with MRB}

Table 4 reports a univariate analysis of the examined risk factors for MRB carriage for each bacterium. Since the number of colonised patients was low, we were only able to identify risk factors associated with MRB at multivariate level for ESBL. For CPE only four patients were identified, all were males and all had been admitted to hospital within the last 6 months. The risk of MRSA was increased among patients with chronic respiratory infections and patients previously colonised with MRSA. For VRE antibiotic treatment within past month, antibiotic treatment during the current admission, chronic obstructive pulmonary disease, treatment at a hospital in Nordic countries within last 6 months and treatment with antibiotics outside Nordic countries within the last 6 months were risk factors. The multivariate analysis reported that ESBL was associated with chronic respiratory infections, treatment with antibiotics outside Nordic countries and travel activity in Asia/Oceania.

\section{DISCUSSION}

We found that among 5117 patient visits to Danish EDs, 266 (5.2\%) had MRB, most commonly ESBL (4.5\%), followed by VRE $(0.4 \%)$, MRSA $(0.3 \%)$ and CPE $(0.08 \%)$. There were significant differences between the regions (from $3.9 \%$ to $6.5 \%$ ), but not between type of hospital, age or gender.

Concerning risk factors for MRB, treatment with antibiotics within the last month (ESBL and VRE), chronic respiratory infections (MRSA and ESBL), treatment with antibiotics outside Nordic countries within the last 6 months (CPE, ESBL and VRE), especially if the patient had been admitted to foreign hospital (CPE and ESBL) and travel activities to Asia/Oceania and Africa (ESBL) were associated with MRB.

The prevalence of antibiotic resistance is high in the southern and eastern parts of Europe and relatively low in the northern parts, especially in the Scandinavian countries and the Netherlands. ${ }^{2}$ The low carrier prevalence 


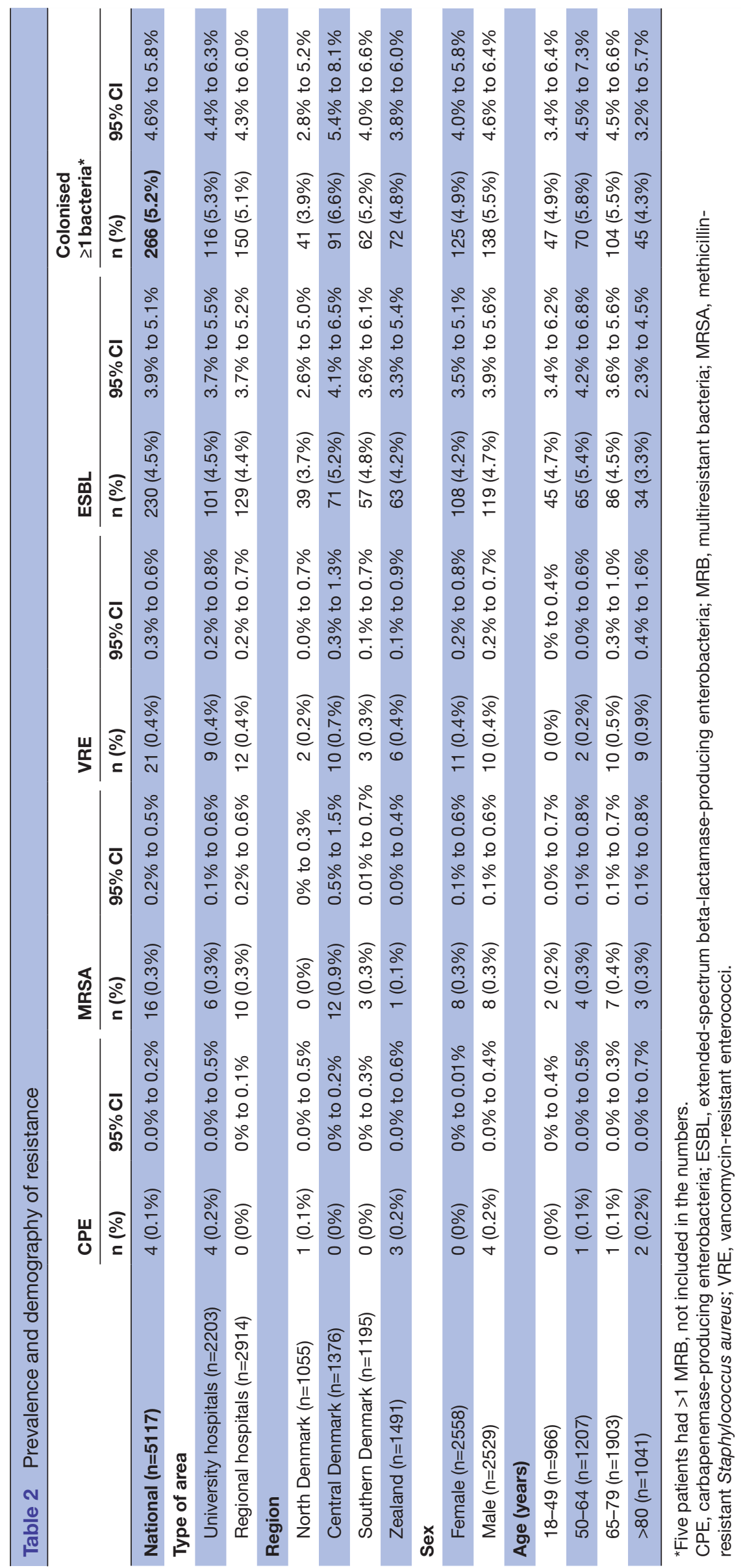


Table 3 Number of in vitro susceptible isolates $(\%)^{*}$

\begin{tabular}{|c|c|c|c|c|c|c|c|}
\hline & Species & $\begin{array}{l}\text { Number of } \\
\text { isolatest }\end{array}$ & Meropenem & $\begin{array}{l}\text { Piperacillin- } \\
\text { tazobactam }\end{array}$ & Gentamicin & Ciprofloxacin & Beta-lactamase \\
\hline \multirow[t]{4}{*}{ ESBL $n=247$} & Escherichia coli & 203 & $203(100)$ & $175(86)$ & $153(75)$ & $97(48)$ & na \\
\hline & $\begin{array}{l}\text { Klebsiella } \\
\text { pneumoniae }\end{array}$ & 35 & $34(97)$ & $17(49)$ & $26(74)$ & $6(17)$ & nał \\
\hline & $\begin{array}{l}\text { Klebsiella } \\
\text { oxytoca }\end{array}$ & 6 & $6(100)$ & $4(67)$ & $2(33)$ & $1(17)$ & na \\
\hline & Other§ & 2 & $2(100)$ & 1 & 1 & 1 & na \\
\hline \multirow[t]{2}{*}{ CPE $n=6$} & E. coli & 3 & 0 & 0 & $1(33)$ & 0 & $\begin{array}{l}\text { OXA-48 (2), } \\
\text { NDM (2)ף }\end{array}$ \\
\hline & Other ${ }^{\star \star}$ & 3 & 0 & 0 & $2(67)$ & 0 & NDM (3) \\
\hline
\end{tabular}

${ }^{*}$ According to European Committee on Antimicrobial Susceptibility testing (EUCAST) breakpoints (www.eucast.org).

†Eleven patients were colonised with more than one ESBL-producing enterobacteria and two patients were colonised with two different CPE (different species or susceptibility pattern).

$\S$ One Klebsiella spp, and one Citrobacter koseri.

fOne isolate of $K$. pneumoniae was both ESBL and New Delhi metallo-beta-lactamase (NDM) positive.

ПOne isolate was both oxacilinase-48 (OXA-48) and NDM positive.

${ }^{\star *}$ One Enterobacter cloacae, one K. pneumoniae and one Citrobacter freundii.

CPE, carbapenemase-producing enterobacteria; ESBL, extended-spectrum beta-lactamase-producing enterobacteria; na, not available.

in Denmark probably reflects a long tradition for antimicrobial stewardship and restrictive use of antimicrobial drugs.

In the present study, median age is much higher than in the general population, since it is mostly older adults who visit the ED. Consumption of antimicrobial drugs is a risk factor for colonisation with MRB and thus the carrier prevalence in our study is presumed to be higher than the carrier prevalence in the community as the use of antibiotics is expected to be relatively high in elderly patients. The opposite might apply to MRSA as a large proportion of community-acquired MRSA in Denmark is associated with livestock contact and thus may be associated with a younger, working population.

The literature has mainly focused on the prevalence in patients admitted to the wards and less on acute patients. The carrier prevalence of ESBL has been reported $1 \%-18 \%{ }^{15-18}$ and risk factors for ESBL are admission to geriatric department, living in metropolitan area, recent antibiotic use, urinary catheter use, high level of care dependency, hospitalisation abroad and multiple hospital contacts, ${ }^{15-19}$ which is in line with our results. The prevalence of ESBL has been reported low in two UK studies ${ }^{2021}$ but $7 \%-30 \%$ in other studies. ${ }^{22-24}$ Reported risk factors are long hospital stays, recent antibiotic use and hospitalisation abroad. ${ }^{19} 2124$ The prevalence of VRE has been reported from $0 \%$ to $25 \%{ }^{16202526}$ and risk factors for VRE colonisation are increasing age, long hospital stay, invasive devices and use of antibiotics. ${ }^{26}$ In a Danish ED in 2015, an MRSA prevalence of $0.9 \%$ was reported. ${ }^{13}$ This prevalence is higher than the prevalence reported in the present study, which clearly conflicts with a general increase in the number of new cases of community-acquired MRSA in Denmark. ${ }^{4}$ The reason is unknown but might reflect a temporary high local prevalence in 2015.
In comparison, other studies have reported a prevalence of 2\%-8\%. ${ }^{151627}$ Reported risk factors are chronic wounds, high level of care dependency, recent antibiotic use, readmission, previous MRSA colonisation, contact to living pigs, daily contact with children at nursery/kindergarten and renal failure. ${ }^{152728}$

Despite the lack of studies investigating the prevalence in acute adult patients, the ED is thought to be a low prevalence department of MRB since the majority of patients come from the community. ${ }^{29}{ }^{30}$ However, patients from nursing homes are frequently admitted and are reported to have a higher MRB carrier prevalence. ${ }^{31-33}$

\section{Clinical considerations}

On average, 1 out of 20 patients arriving to a Danish ED brings MRB to the hospital, which means that every day several patients will be handled with MRB. The current Danish screening programmes aim to identify MRSA and CPE, which are seen in fewer than 1:300 and 1:1250 patients, respectively, suggesting that these patients are managed in the ED on a weekly or monthly basis only.

ESBL is currently the most frequent colonising MRB in the Danish EDs and careful monitoring of the incidence of ESBL infections is important to assess empirical antibiotic strategies. However, contact isolation is probably not required to prevent transmission of ESBL to other patients or staff in settings with a high standard in general and universal infection control. ${ }^{34}$

MRSA and CPE screening programmes based on patient information concerning risk situations are time consuming. ${ }^{28}$ The low MRB prevalence in this study suggests that the positive predictive value of these screening programmes could be very low leading to unnecessary interventions and contact isolations. This might affect the questions in the patient interview or 


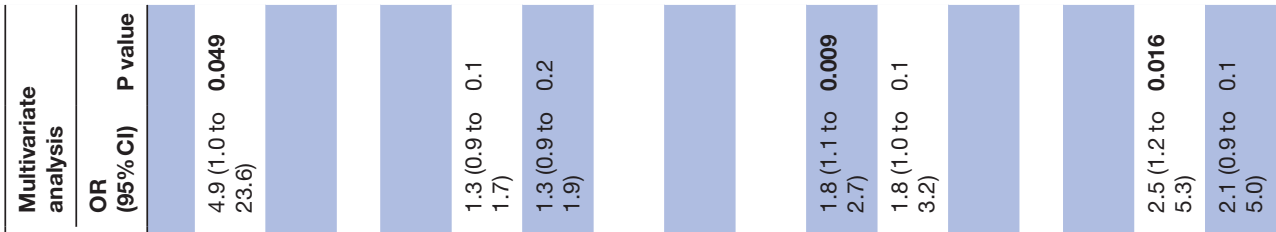

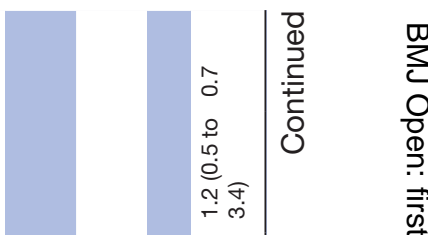

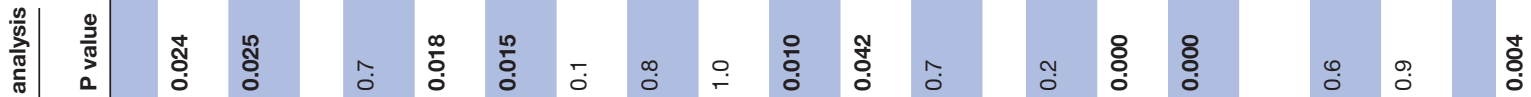

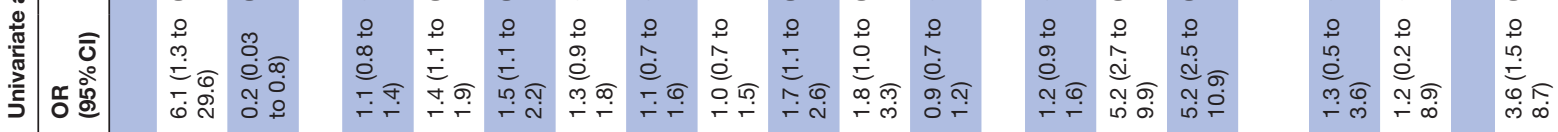

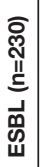

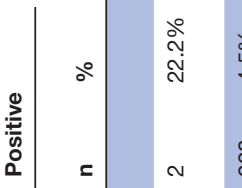

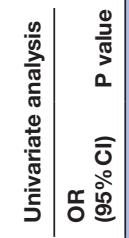

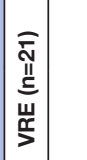

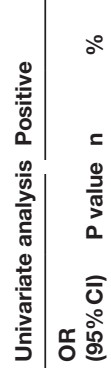

ஃั

\section{0}

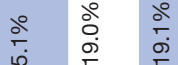

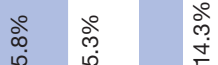

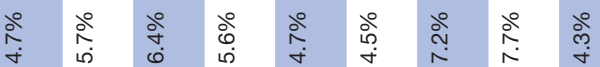

8 웅

-

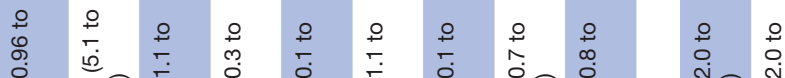

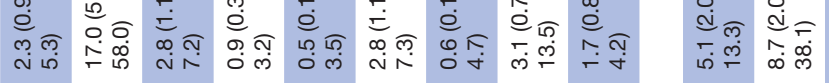

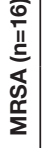

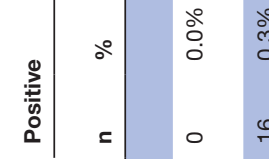

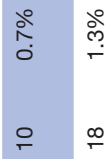

กู่ ว

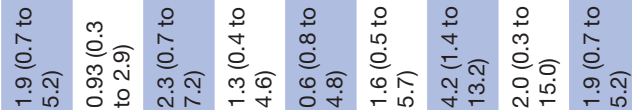

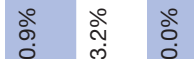

ㅇํㅇ

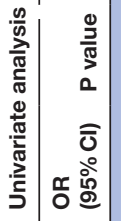

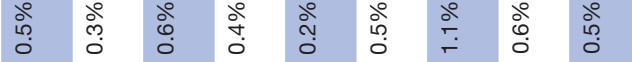

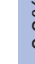

$\stackrel{n}{\circ}$

$\stackrel{10}{0}+\overline{0}$

: :

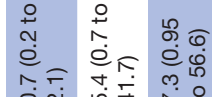

ำ

이에

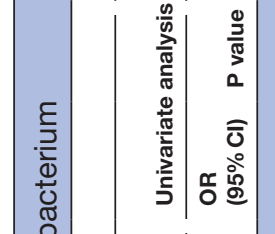

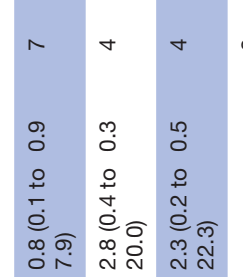

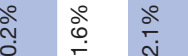

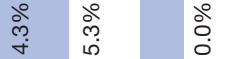

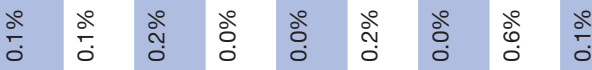

(1)

ஷั

○े

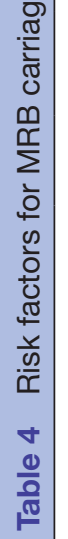

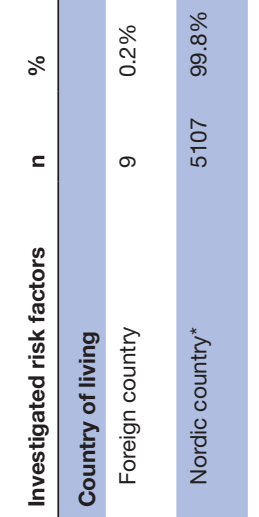

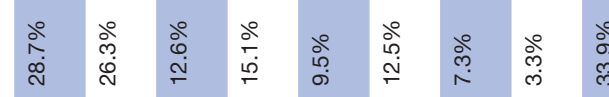

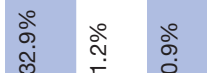

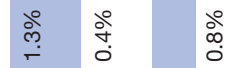

年 总

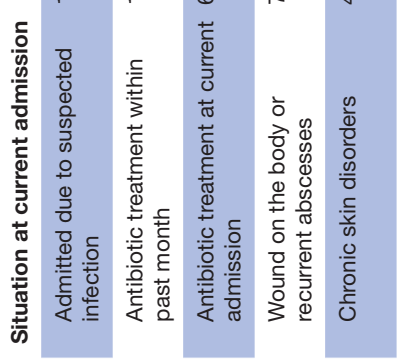

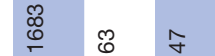

$8 \stackrel{\text { ช }}{\circ}$
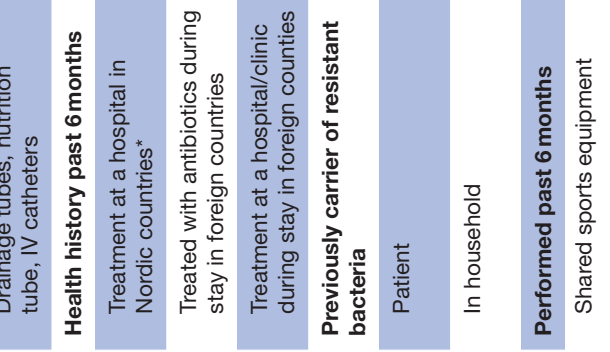


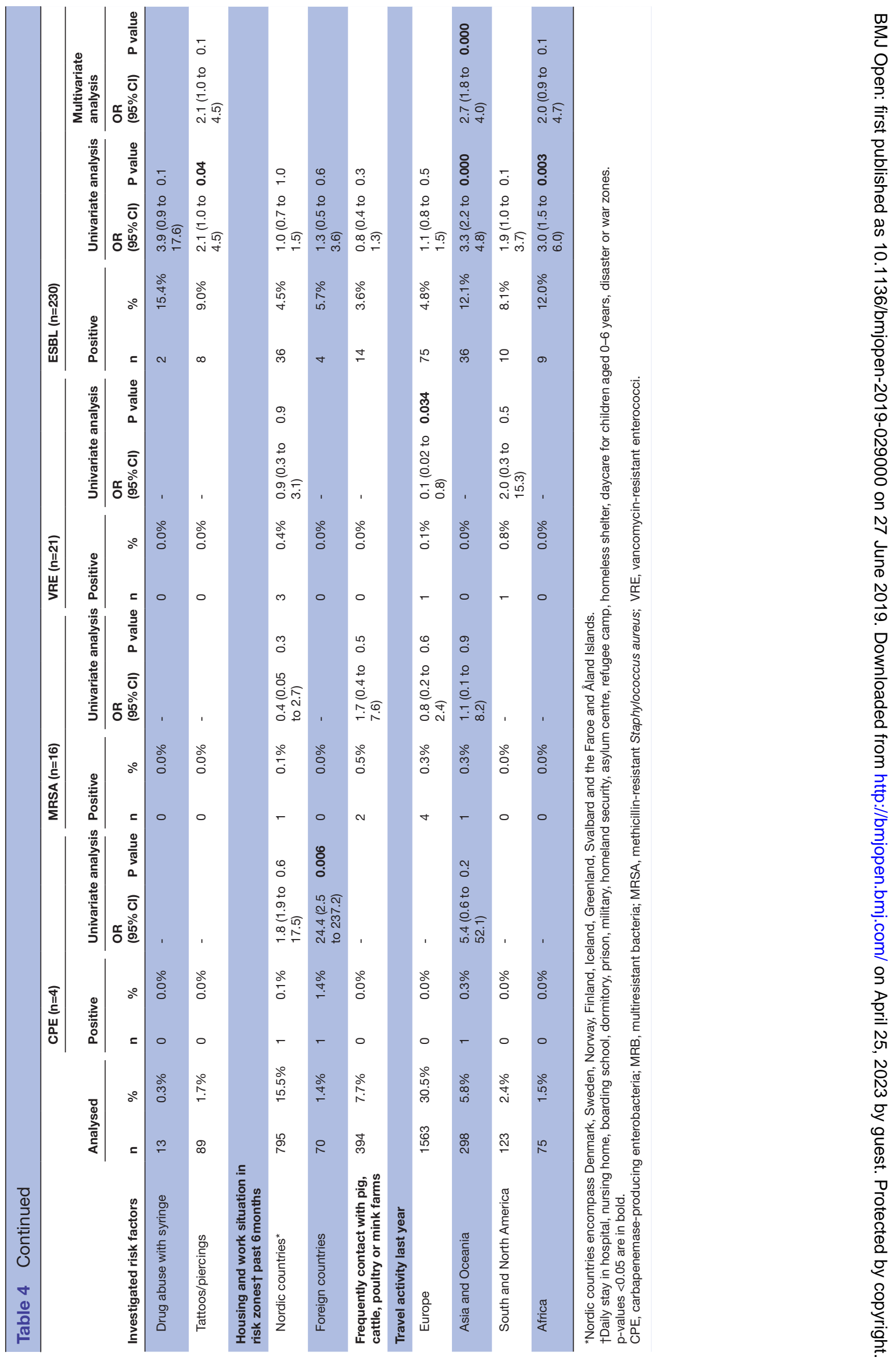


which bacteria to identify in the current screening programmes. This question will be addressed in another part of the AB-RED study.

The geographical variation in the prevalence of MRB might reflect variations in antibiotic use. In this study, we did not investigate the type of administered antibiotics or the duration of treatment prior to enrolment. These questions will be addressed in another part of the AB-RED study.

As travelling outside the Nordic countries is a risk factor for MRB colonisation, it seems rational that the national screening guidelines recommend screening of patients who have received antibiotics or in-hospital treatment outside the Nordic countries. Unfortunately, since patients transferred directly from foreign hospitals usually bypass the EDs and are admitted directly to the wards they are not included in this study.

\section{Strengths and weaknesses}

The strength of the present study is that it is the first study to describe and analyse a large number of possible risk factors in acute adult patients screened for ESBL, VRE, MRSA and CPE. It is a large, semi-national multicentre study covering the main part of Denmark. Furthermore, the same methods for collecting information and biological material and for microbiological testing were applied to all included departments/patients.

However, this study has also some limitations. First, while we aimed to include at least 5000 patient contacts, the optimal and expected inclusions were 10000 , as mentioned in the study protocol. ${ }^{11}$ This means that many of the results are reported with some degree of uncertainty, reflected in wide CIs, especially in subgroup analysis of regional prevalences. Second, we only tested a sample of patients visiting the ED mainly on working days and only during day/evening time. We are therefore not able to describe the occurrences of MRB outside these periods. We do believe however, that time of admission is not influenced by MRB carrier stage. Third, the study did not include all patient contacts to ED during the collection periods, as only subset of patients could be managed by the study staff. This represents a possible selection bias but we do not have access to data which can be used to clarify this. Fourth, 28\% declined to participate after being invited to the study, mainly because of no interest in the study. It was the study staffs' impression that other major reasons were the unpleasant rectal swab test and acute illness and fatigue. The results of the study might therefore represent a less ill ED population. A language barrier was the cause of exclusion in 32 patients. In Denmark, many workers in pig farms are often not Danish speaking. We do not know if there is a selection bias in this case. Furthermore, since more female patients and patients with internal medical complaints refused to participate, the results of the study might not represent the total population of patients in the ED. An inclusion criterion was mentally competent. This criterion precludes patients with dementia, which usually stay in long-term care facilities where the MRB prevalence might be higher. Sixth, the questions are based on past events and require a certain level of recall ability for the acute ill patient.

Finally, the external validity of this study is restricted to countries with a low MRB prevalence.

\section{CONCLUSION}

Every 20th patient in a Danish ED brings MRB to the hospital, which means that every day several patients will be handled with MRB. ESBL is the most frequent MRB in the ED. Risk factors for MRB are recent use of antibiotics, chronic respiratory infections, recent treatment with antibiotics outside Nordic countries and travel activities to Asia/Oceania.

\section{Author affiliations}

${ }^{1}$ Department of Regional Health Research, University of Southern Denmark, Odense, Denmark

${ }^{2}$ Emergency Department, Hospital Sønderjylland, Aabenraa, Denmark

${ }^{3}$ Department of Emergency Medicine, Odense University Hospital, Odense, Denmark ${ }^{4}$ Department of Infectious Diseases, Odense University Hospital, Odense, Denmark

${ }^{5}$ Department of Clinical Microbiology, Hospital Sønderjylland, Soenderborg,

Denmark

${ }^{6}$ Regional Hospital West Jutland, Herning, Denmark

${ }^{7}$ Emergency Department, Aarhus University Hospital, Aarhus, Denmark

${ }^{8}$ Department of Clinical Microbiology, Aarhus University Hospital, Aarhus, Denmark

${ }^{9}$ Emergency Department, Aalborg University Hospital, Aalborg, Denmark

${ }^{10}$ Emergency Department, North Denmark Regional Hospital, Hjørring, Denmark

${ }^{11}$ Department of Clinical Microbiology, Aalborg University Hospital, Aalborg,

Denmark

${ }^{12}$ Emergency Department, Slagelse Sygehus, Slagelse, Denmark

${ }^{13}$ Emergency Department, Zealand University Hospital, Køge, Denmark

${ }^{14}$ Department of Clinical Microbiology, Slagelse Sygehus, Slagelse, Denmark

${ }^{15}$ Department of Clinical Microbiology, Odense University Hospital, Odense, Denmark

Contributors HS-A, CBM, FSR, ATL, MC and ISJ conceptualised and all authors designed the study and data collection instrument in detail. HS-A, ATL, PP, KVA, JMM, ML, FEN and DBP supervised data collection. SE-E, DF-D, USJ and FSR supervised the microbiological analysis. HS-A, CBM and FSR participated in data analysis, and HS-A and CBM contributed to manuscript development. HS-A, CBM, ATL, ISJ, MC, PP, KVA, SE-E, JMM, ML, DF-D, FEN, DBP, USJ and FSR participated in the critical scrutiny and revision of the manuscript, and approved the final version. HS-A, CBM and FSR are responsible for the overall content as guarantors. The corresponding author attests that all listed authors meet authorship criteria and that no others meeting the criteria have been omitted.

Funding This work was supported by the Ministry of Health Denmark and Region of Southern Denmark.

Disclaimer The financial sponsors had no influence on the data, analysis, results or content of publication.

Competing interests None declared.

Patient consent for publication Not required.

Ethics approval The project was approved by the Regional Committees on Health Research Ethics for Southern Denmark (no. S-20170182), registered by the Danish Data Protection Agency (Journal nr. 17/44444) and by clinical-trials.gov (NCT03352167).

Provenance and peer review Not commissioned; externally peer reviewed.

Data sharing statement Due to Danish laws on personal data, data cannot be shared publicly. To requestthese data, please contact the corresponding author for more information.

Open access This is an open access article distributed in accordance with the Creative Commons Attribution Non Commercial (CC BY-NC 4.0) license, which permits others to distribute, remix, adapt, build upon this work non-commercially, 
and license their derivative works on different terms, provided the original work is properly cited, appropriate credit is given, any changes made indicated, and the use is non-commercial. See: http://creativecommons.org/licenses/by-nc/4.0/.

\section{REFERENCES}

1 WHO. Antimicrobial resistance: global report on surveillance: World Health Organization, 2014

2. ECDC. Surveillance of antimicrobial resistance in Europe 2017. Stockholm, 2018.

3. Monitoring, D.I.A.R. Research Programme (DANMAP). 2010. Use of antimicrobial agents and occurrence of antimicrobial resistance in bacteria from food animals, food, and humans in Denmark. 2016.

4. DANMAP, DANMAP 2017. Use of antimicrobial agents and occurence of antimicrobial resistance in bateria from food animals, food and humans in Denmark. 2017.

5. Bell BG, Schellevis F, Stobberingh E, et al. A systematic review and meta-analysis of the effects of antibiotic consumption on antibiotic resistance. BMC Infect Dis 2014;14:13.

6. WHO. Global action plan on microbial resistance, 2015

7 Levy SB. Antibiotic resistance: consequences of inaction. Clin Infect Dis 2001;33 Suppl 3:S124-9.

8. Dubinsky-Pertzov B, Temkin E, Harbarth S, et al. Carriage of extended-spectrum beta-lactamase-producing Enterobacteriaceae and the risk of surgical site infection after colorectal surgery: a prospective cohort study. Clin Infect Dis 2018.

9. Montassier E, Batard E, Gastinne T, et al. Recent changes in bacteremia in patients with cancer: a systematic review of epidemiology and antibiotic resistance. Eur J Clin Microbiol Infect Dis 2013;32:841-50.

10. Mikulska M, Del Bono V, Raiola AM, et al. Blood stream infections in allogeneic hematopoietic stem cell transplant recipients: reemergence of Gram-negative rods and increasing antibiotic resistance. Biol Blood Marrow Transplant 2009;15:47-53.

11. Mogensen CB, Skjøt-Arkil H, Lassen AT, et al. Cross sectional study of multiresistant bacteria in Danish emergency departments: prevalence, patterns and risk factors for colonization (AB-RED project). BMC Emerg Med 2018;18:25.

12. Vandenbroucke JP, von Elm E, Altman DG, et al. Strengthening the Reporting of Observational Studies in Epidemiology (STROBE): explanation and elaboration. Int J Surg 2014:12:1500-24.

13. Mogensen CB, Kjældgaard $P$, Jensen $C$, et al. MRSA screening in emergency department detects a minority of MRSA carriers. Dan Med J 2015;62:A30.

14. Sundhedsstyrelsen. Vejledning om forebyggelse af spredning af MRSA. 2016 https://www.sst.dk/da/sygdom-og-behandling/ smitsomme-sygdomme/mrsa/ /media/430A2A77872E479FA9EB C42A5E053BFC.ashx.

15. Schoevaerdts D, Verroken A, Huang TD, et al. Multidrug-resistant bacteria colonization amongst patients newly admitted to a geriatric unit: a prospective cohort study. J Infect 2012;65:109-18.

16. Young BE, Lye DC, Krishnan $\mathrm{P}$, et al. A prospective observational study of the prevalence and risk factors for colonization by antibiotic resistant bacteria in patients at admission to hospital in Singapore. BMC Infect Dis 2014;14:298.

17. Pilmis B, Cattoir V, Lecointe D, et al. Carriage of ESBL-producing Enterobacteriaceae in French hospitals: the PORTABLSE study. $J$ Hosp Infect 2018;98:247-52.

18. Enoch DA, Brown F, Sismey AW, et al. Epidemiology of extendedspectrum beta-lactamase-producing Enterobacteriaceae in a UK district hospital; an observational study. J Hosp Infect 2012;81:270-7.

19. Khawaja T, Kirveskari J, Johansson S, et al. Patients hospitalized abroad as importers of multiresistant bacteria-a cross-sectional study. Clin Microbiol Infect 2017;23:673.e1-673.e8.

20. Wilson HJ, Khokhar F, Enoch DA, et al. Point-prevalence survey of carbapenemase-producing Enterobacteriaceae and vancomycinresistant enterococci in adult inpatients in a university teaching hospital in the UK. J Hosp Infect 2018;100:35-9.

21. Otter JA, Dyakova E, Bisnauthsing KN, et al. Universal hospital admission screening for carbapenemase-producing organisms in a low-prevalence setting. J Antimicrob Chemother 2016;71:3556-61.

22. Salomão MC, Guimarães T, Duailibi DF, et al. Carbapenemresistant Enterobacteriaceae in patients admitted to the emergency department: prevalence, risk factors, and acquisition rate. J Hosp Infect 2017;97:241-6.

23. Perez LR, Rodrigues D, Dias CG. Evaluation of phenotypic tests to detect carbapenem-resistant Enterobacteriaceae in colonized patients hospitalized in intensive care units. Braz $J$ Infect Dis 2015;19:436-8.

24. Yamamoto N, Asada R, Kawahara R, et al. Prevalence of, and risk factors for, carriage of carbapenem-resistant Enterobacteriaceae among hospitalized patients in Japan. J Hosp Infect 2017;97:212-7.

25. Whelton E, Lynch C, O'Reilly B, et al. Vancomycin-resistant enterococci carriage in an acute Irish hospital. J Hosp Infect 2016;93:175-80.

26. Forde C, Stierman B, Ramon-Pardo P, et al. Carbapenem-resistant Klebsiella pneumoniae in Barbados: Driving change in practice at the national level. PLoS One 2017;12:e0176779.

27. Aizen E, Ljubuncic Z, Ljubuncic $P$, et al. Risk factors for methicillin-resistant Staphylococcus aureus colonization in a geriatric rehabilitation hospital. J Gerontol A Biol Sci Med Sci 2007;62:1152-6.

28. Mogensen CB, et al. Simplified screening in an emergency department detected methicillin-resistant Staphylococcus aureus. Dan Med J 2016;63.

29. Nüesch-Inderbinen M, Zurfluh K, Hächler H, et al. No evidence so far for the dissemination of carbapenemase-producing Enterobactericeae in the community in Switzerland. Antimicrob Resist Infect Control 2013;2:23.

30. Andersson $\mathrm{H}$, Lindholm C, Iversen A, et al. Prevalence of antibioticresistant bacteria in residents of nursing homes in a Swedish municipality: healthcare staff knowledge of and adherence to principles of basic infection prevention. Scand J Infect Dis 2012;44:641-9.

31. Peters C, Dulon M, Kleinmüller O, et al. MRSA Prevalence and Risk Factors among Health Personnel and Residents in Nursing Homes in Hamburg, Germany - A Cross-Sectional Study. PLoS One 2017;12:e0169425.

32. Neumann N, Mischler D, Cuny C, et al. [Multidrug-resistant organisms (MDRO) in patients in outpatient care in the RhineMain region, Germany, in 2014: Prevalence and risk factors] Bundesgesundheitsblatt Gesundheitsforschung Gesundheitsschutz 2016;59:292-300.

33. McKinnell JA, Miller LG, Singh R, et al. Prevalence of and Factors Associated With Multidrug Resistant Organism (MDRO) Colonization in 3 Nursing Homes. Infect Control Hosp Epidemiol 2016;37:1485-8.

34. Tschudin-Sutter S, Frei R, Dangel M, et al. Rate of transmission of extended-spectrum beta-lactamase-producing enterobacteriaceae without contact isolation. Clin Infect Dis 2012;55:1505-11. 